\title{
Crise, crítica e reflexividade: problemas conceittuais e teóricos na produção de diagnósticos de época
}

\section{Felipe Maia* (1)}

\section{Resumo}

Há na bibliografia recente de sociologia e ciências sociais um interesse renovado no conceito de crise, como parte dos esforços para compreensão de tendências de desenvolvimento que se desdobram no tempo, usualmente associadas à produção de "diagnósticos de época". Há, entretanto, ainda pouco esclarecimento sobre o sentido que o conceito assume na teoria social, permanecendo incerta sua relação com problemas funcionais e normativos, assim como sua própria utilidade para a qualificação do tempo histórico. O artigo trata dessas questões a partir da comparação entre as abordagens de Reinhart Koselleck e Jürgen Habermas, que são mobilizadas para se pensar as possibilidades de desenvolvimento do conceito de crise. Argumenta-se que ele deve ser compreendido no escopo de teorias dos processos e mudanças sociais, referindo-se a momentos específicos no tempo em que se conjugam problemas normativos e funcionais, sem que isso implique um pressuposto dualista de percepção do mundo social, sob os critérios de instabilidade e estabilidade. Argumenta-se também que, embora a história dos conceitos afirme a relação entre crítica e crise, é prudente evitar a conflação entre os dois conceitos e situar a crítica como um dos modos possíveis de reflexividade em períodos de crise, o que traria vantagens para uma melhor compreensão das possibilidades da teoria crítica e da crítica social em tempos de crise.

Palavras-chave: crise, crítica, reflexividade, diagnósticos de época, teoria social.

* Universidade Federal de Juiz de Fora, Juiz de Fora, MG, Brasil. 


\section{Crisis, critique and reflexivity: conceptual and theoretical problems in diagnoses of times}

Abstract

Recent works in sociology and social sciences show a renewed interest in the concept of crisis, as part of the efforts to understand developmental tendencies in time, usually connected to diagnoses of times. However, the concept of crisis sometimes is not completely clear. Its relation to functional and normative problems remains uncertain, as though its usefulness to qualify historical time. The article addresses these questions from a comparative reading of the works of Reinhart Koselleck and Jürgen Habermas, mobilizing it to think about the concept of crisis. I argue that this concept should be understood in the scope of social change and social processes theories, related to specific moments in time when normative and functional problems are linked, without dualist presupposes of instability and stability. I argue also that although the history of the concept shows the relations between crisis and critique, we should not conflate the concepts. Critique should be situated as one of the possible modes of reflexivity in times of crisis. This should be a vantage point to better understanding the possibilities of critical theory and social critique in these times.

Keywords: crisis, critique, reflexivity, diagnoses of times, social theory.

\section{Introdução}

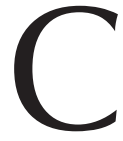

rise tornou-se uma palavra quase onipresente, seja nos meios de comunicação ou nos títulos de livros e artigos de sociologia, para não falar das conversas cotidianas. Ao que parece, tudo está em crise e há um sentimento generalizado de crise em esferas diversas da vida social. Esse retorno da sensação de crise tem merecido um esforço reflexivo valoroso entre cientistas sociais ${ }^{1}$, para o qual esperamos poder contribuir. Se formos buscar uma referência temporal, desde ao menos os eventos que marcaram a explosão dos mercados financeiros em 2007-2008, ganharam relevo na discussão sociológica temas associados à crise do capitalismo,

1 Ver especialmente Cordero (2014), Cordero, Mascareño e Chernilo (2017), Dobry (2014), Jessop (2016), Roitman (2016), Runciman (2016), Streeck (2014), Wagner (2012), Walby (2015), Wallerstein (2013). 
que em seguida se tornaria crise da democracia e aguçaria ainda mais a consciência da crise ecológica e ambiental.

No conjunto, esses processos têm motivado certa inflexão na teoria social - a tentativa de produzir "diagnósticos de época", um tanto marginalizada no período anterior, voltou a ganhar relevância e, com ela, uma nova valorização de "grandes narrativas" e de perspectivas macrossociológicas, para além do campo mais especializado da sociologia histórica, que procuram dar inteligibilidade às muitas crises. Nelas os planos dos processos, das estruturas e da ação vão sendo urdidos com ênfases distintas, no intuito de oferecer um quadro interpretativo capaz de identificar causalidades e tendências, bem como identificar valores que podem ser protegidos, e imaginar alternativas. Esforço que se beneficia da conexão tanto com os "clássicos" da sociologia, quanto com outras tradições disciplinares, notadamente a história e a filosofia.

Mas, as ambiguidades do conceito de crise podem dificultar o trabalho teórico e analítico, razão pela qual se justifica o esforço de análise conceitual. Não se trataria de procurar "estabilizar" o conceito para que ele pudesse se tornar perfeitamente operacional, mas de compreender, como parte do esforço de uma maior reflexividade sociológica, suas aporias e possibilidades de uso, avaliando possíveis abordagens. Isso pode ajudar a evitar a inflação do conceito e sua reificação, ao conferir-lhe um lugar apropriado no vocabulário das ciências sociais, diferenciando-o, inclusive, de outros termos, tais como contradição, conflito, catástrofe ou risco. Com isso poderíamos contribuir também para uma comunicação entre a teoria social e a consciência pública de problemas sociais, valorizando as múltiplas hermenêuticas a que a ciência social está sujeita. Neste artigo, procuro trabalhar o tema tomando como referência uma comparação entre as concepções de crise e crítica em Koselleck (1999; 2006) e Habermas (1988) e a forma como eles as mobilizaram para produzir diagnósticos de época. Ao final, procuro mostrar como esses temas retornam no debate contemporâneo e oferecer alguns caminhos para desenvolver o problema conceitualmente. 
De início, é preciso esclarecer o conceito de diagnóstico de época ${ }^{2}$ que conforma o quadro mais amplo no qual situamos a discussão sobre crise e crítica. O conceito designa um trabalho intelectual que excede as fronteiras disciplinares, compreendendo não só a sociologia, a história e a filosofia, mas também a estética e a crítica literária, e que quer capturar as "marcas do tempo" (Lichtblau, 2017). De acordo com Hammershoj (2015), é um tipo de trabalho focado na interpretação de tendências de desenvolvimento que se desdobram no tempo e na análise das condições em que certas práticas sociais podem se desenvolver. Em seu momento emergente, no século XIX, a sociologia incorpora a produção de diagnóstico de época ao afirmar seu interesse na interpretação das mudanças associadas às novas formações sociais da modernidade, o que sugere que a relação da disciplina com essa prática é constitutiva e não simplesmente externa. Com ela desenvolvem-se ambiguidades, pois a pretensão científica da disciplina se choca com a de servir como um meio reflexivo para o autoentendimento das sociedades modernas, o que se agrava pela relação pouco clara que a sociologia mantém com a história, enquanto reclama um acesso privilegiado à "situação do tempo" (Lichtblau, 2017).

Para Habermas (2015), em seu momento inaugural, a sociologia alemã comportava essa ambiguidade, constituindo-se como disciplina e "superdisciplina", isto é, como teoria social e como teoria da sociedade, por isso seus conceitos-chave, tais como comunidade e sociedade, e racionalidade com respeito a fins ou valores, foram construídos "de modo que a teoria da ação social e das relações sociais podia dar respostas a questões complexas relativas ao diagnóstico de época" (Habermas, 2015, p. 287), revelando as ambivalências do processo histórico de modernização. Esse entrelaçamento entre teoria e diagnóstico é que conformaria as características centrais do trabalho sociológico de então, como o "interesse pelas patologias,

${ }^{2}$ Aqui também nos defrontamos com uma expressão corrente cujo sentido nem sempre é explicitado e até mesmo a tradução dos equivalentes em alemão (Zeitdiagnose) ou em inglês (diagnose of times) varia em língua portuguesa entre as expressões diagnóstico de época ou do tempo. 
paradoxos e crises" (p. 287), a reflexão sobre as tradições intelectuais precursoras, a combinação entre a perspectiva histórica e a sistemática, os problemas da relação entre teoria e metateoria, reunidos de modo exemplar nos escritos de Max Weber. Desde então, o autoentendimento do trabalho sociológico se diferenciou e esses elementos se autonomizaram. No entanto, o interesse por diagnósticos de época se mantém, ainda que as condições de sua produção sejam outras, afastados os pressupostos da filosofia da história a respeito das condições de acesso à totalidade do mundo social, que informaram os diagnósticos filosóficos, e transformadas as condições disciplinares da sociologia. Este já não seria mais assunto "a ser perseguido impunemente com intenctione recta" (Habermas, 1987, p. 4), mas poderia estar associado ao trabalho coletivo, a uma abordagem mais modesta, consciente da necessidade de embasamento empírico e de sua relatividade hermenêutica (Habermas, 1987). Dois balanços recentes (Lichtblau, 2017; Hammershoj, 2015) apontam a fecundidade dos diagnósticos de época como formas de reflexividade e de autoentendimento das sociedades modernas, o que se reforça com o interesse recente no debate sobre crise. Em Koselleck é clara a função "diagnóstica" do conceito de crise, cuja semântica está historicamente associada às teorias medicinais da crise; ${ }^{3} \mathrm{e}$, na medida em que Koselleck não só expõe o conceito, mas o utiliza, ele também compartilha a prática intelectual da produção de diagnósticos de época, como exporei a seguir.

\section{Koselleck, as ambiguidades da crítica e a crise}

A abordagem da história dos conceitos de Reinhardt Koselleck (1999; 2006) sobre crítica e crise tem sido eficaz para mostrar a interdependência entre os conceitos, suas ambiguidades no que diz respeito a questões de temporalidade e as múltiplas formas de uso que adquiriram na linguagem política e filosófica do Ocidente. Para além disso, quero argumentar que

${ }^{3}$ Mannheim (2010 [1943]) é outra referência para o uso da expressão "diagnóstico de época", com a adoção explícita das metáforas medicinais do diagnóstico e da crise. Sobre o uso do conceito em Mannheim, ver também Lichtblau (2017). 
seu estudo compartilha elementos dessa tradição intelectual, de modo que seu Crítica e crise (Koselleck, 1999) pode ser visto também como um estudo exemplar da produção de diagnósticos de época, tema que foi explicitado na introdução do livro e no diálogo que manteve naquele período com Carl Schmitt. Assim, Koselleck pode ajudar-nos a compreender algumas das dimensões dos conceitos e deste tipo de trabalho intelectual, a produção de diagnósticos de época.

Em seu livro, Koselleck (1999) argumenta que aquilo que a linguagem do século XX separa como crítica "subjetiva" e crise "objetiva", no grego antigo eram compreendidos sob um conceito comum. Embora não fosse originariamente um conceito jurídico, "krisis" apontava para um momento de cisão e luta, mas também de decisão, de modo que se referia intrinsecamente a uma atividade de julgar, de ponderar "prós e contras" e produzir um juízo e uma decisão - o que hoje estaria mais próximo das atividades do juiz ou do crítico de arte. A ênfase está no nexo entre esses dois momentos - Koselleck (1999) mostra que Aristóteles, por exemplo, remetia a ideia de "krisis" às decisões judiciais que têm o efeito de "criar a ordem", evidenciando a conexão com a política. Essa acepção jurídica do termo permanece em seu uso na teologia cristã, na qual crise remete ao Juízo Final, ao tribunal universal. Todavia, esse nexo vai se perder na argumentação dos filósofos iluministas no século XVIII, quando a palavra "crise" quase some do discurso corrente e a "crítica" torna-se onipresente, o que aparece como um sintoma da desconexão entre o ato de julgar e a tomada de decisão política. A crítica mantinha o sentido de capacidade de avaliar e julgar, mas raramente aparecia associada ao conceito de crise, o qual era visto pelos autores da Encyclopédie, Diderot e D’Alembert - a partir de sua tradução latina, que o trata como um conceito da medicina e não da política - como o estágio de uma "doença" em que "se decidirá o que ainda não está decidido" (Koselleck, 1999, p. 203). É por esse caminho que o conceito retornaria ao campo da política, frequentando, por exemplo, o vocabulário das cartas e panfletos da revolução americana ("the crisis"), sendo os sintomas de crise o prenúncio de uma alternativa 
entre vida e morte de um parlamento, de um Estado ou de um governo. Para Koselleck (1999), essa dissociação entre crítica e crise no vocabulário filosófico e político do século XVIII estaria a indicar um problema maior, a separação entre moralidade e política, remetendo a atividade da crítica ao terreno da moral, desvinculado de suas responsabilidades políticas.

O argumento de Koselleck (1999) é que essa separação tem relação com a solução oferecida pelo Estado absolutista ao problema da guerra civil e que pode ser acompanhada pela leitura da filosofia política de Thomas Hobbes, para quem a aquisição da paz, com a supressão da guerra civil, é a finalidade moral do arranjo estatal. No entanto, ela se faz ao preço de uma separação entre as convicções privadas e as relações políticas. Isso porque Hobbes compreende que a guerra civil tem origem no conflito entre as convicções dos indivíduos, que fornece a energia e a motivação para a formação dos "partidos" e para a luta. Não se pode, então, sustentar a paz com base nas convicções, mas numa autoridade política soberana incontrastável, à qual é moral obedecer - o que possibilitaria a coincidência entre moral e política. Entretanto, esse arranjo desloca o conflito entre consciência e política para fora do Estado e consagra a cisão do indivíduo em homem privado e cidadão do Estado. A motivação da obediência não está na convicção, mas no poder temporal, um mandamento dado pela situação política. A consciência pode ser livre, desde que em segredo, na esfera privada. O espaço público torna-se neutro em relação às convicções morais dos cidadãos, mas ao preço de tornar a convicção politicamente irrelevante. Todavia, a moralidade recalcada para a esfera privada volta sob a forma de crítica.

Para Koselleck (1999), a crítica se desenvolve a partir da esfera privada, à qual o Estado absolutista havia relegado os súditos, e o Esclarecimento representaria um passo para fora desses limites, à medida que expande o foro interior para o domínio público, reconfigurado como um fórum da sociedade que, no entanto, não renuncia a seu caráter não político de sociedade "privada", não estatal, mas que bate à porta do Estado e reivindica "publicidade". Rompe-se aí a relação de unidade entre moralidade 
e política, pois aquela não é mais a obediência, mas uma afronta e um juízo das leis do Estado, apoiada na convicção interior. A expansão dessa esfera de formação da opinião e da influência é observada por Koselleck na organização do movimento maçônico, que lhe serve de modelo para uma infraestrutura organizativa e comunicativa que atua de maneira clandestina, nos limites estreitos do Estado absolutista. Nas lojas, a "educação moral" conforma a autocompreensão de superioridade moral de uma burguesia politicamente inferiorizada que legitima a crítica sem que esse juízo assuma uma forma diretamente política.

Esse é um modelo de crítica que conforma moralmente uma jurisdição própria, que tem efeitos políticos, mas não se expõe como diretamente política. Esse modelo abrangeria também a crítica burguesa na "república das letras", o teatro e a crítica artística e a filosofia. Koselleck debate esse ponto a partir de Friederich Schiller (apud Koselleck, 1999, p. 88), para quem "a jurisdição do palco começa onde termina o domínio das leis do mundo", concepção que emancipa o crítico para criticar o presente, e com isso cria um espaço de liberdade absoluta, que só reconhece a autoridade da razão, em que todos são soberanos e podem ser julgados. Na filosofia da história, a noção de progresso oferece à crítica antiabsolutista um sentido de certeza e garantia de êxito em razão de sua superioridade moral, mas mantém seu caráter político dissimulado, o que tem o efeito de agravar a crise e intensificar a crítica.

Conforme Koselleck (1999), é Jean-Jacques Rousseau quem oferece uma saída para que a burguesia possa formar uma consciência política autônoma da crise. Mas sem, no entanto, abandonar a posição de superioridade moral que confere um caráter de inocência política a suas investidas contra o Estado absolutista. A reunificação de moralidade e política na "vontade geral", que se torna o critério para avaliar a legitimidade do poder, seria, para Koselleck (1999), uma espécie de "ditadura ideológica da virtude", na qual os súditos apenas legitimam, por identificação ideológica, as decisões do legislador. 
Esse seria um caso exemplar no qual a atividade da crítica tem um efeito produtivo de crise, seja porque fornece motivações para ações que acirram as tensões e, eventualmente, levam ao conflito, seja porque define as possibilidades de compreensão da situação. A crise política do Estado absolutista seria o resultado de uma agência crítica que assume formas específicas em razão das possibilidades mais estruturais de participação (ou de não participação) política, bem como do modo de conceber as relações entre moralidade e política.

No verbete sobre "Crise" (Koselleck, 2006), a pesquisa sobre os termos se amplia e fornece mais elementos sobre essa concepção. A longa história do conceito revela o predomínio da concepção médica de crise, que se expande, enquanto metáfora, para os campos da política, da economia, da história etc. A ênfase semântica estaria na demanda por uma decisão entre alternativas polares, embora seu uso revele uma percepção do tempo, o "fim de uma época", uma mudança qualitativa que separa e distingue momentos. A consulta aos dicionários alemães no final do século XVIII revelaria três significados principais: a) "mudança no curso de uma doença", b) "ponto decisivo no tempo" e c) "situação alarmante" (Koselleck, 2006, p. 365). Um dos dicionários cita o poeta Goethe (apud Koselleck, 2006, p. 3674), para quem "todas as transições são crise" e se pergunta: "seria uma crise diferente de uma doença?". Essas são acepções do termo que estão em consonância com a concepção médica de crise, importada inicialmente como a crise do "corpo político", cujo uso recorrente revela uma percepção difusa de mudança radical.

Com uso mais diretamente político ganha relevo a conexão com a dimensão da ação. Por exemplo, na análise da sucessão austríaca do imperador Frederico, o Grande, a definição de crise expressa o diagnóstico de uma situação que comporta alternativas distintas para diferentes atores e que oferece uma oportunidade para a ação, de modo que o diagnóstico de crise vira uma fórmula para legitimar a ação política. $\mathrm{O}$ espectro para aplicar o termo podia variar, de questões militares e geopolíticas que

${ }^{4} \mathrm{~A}$ tradução dessa passagem e de outras é do autor do artigo. 
envolviam o balanço de forças entre Estados europeus, até problemas internos de dimensão igualmente variável, a guerra civil ou uma mera troca de governo. Ele serve como "uma categoria descritiva" e como um "critério de diagnóstico para a ação política ou militar":

com respeito a ambos os momentos de julgamento e diagnóstico, bem como prescrição de uma terapia, as origens médicas do termo claramente continuam preservadas em seu uso na linguagem política. Esse permanece o caso até os dias de hoje, embora a determinação do tempo ótimo para decisão seja agora determinada por pressões inescapáveis para agir. Naquele momento, usar o conceito de crise significava reduzir o espaço de manobra, forçando os atores a escolher entre alternativas diametralmente opostas (Koselleck, 2006, p. 370).

O uso político do termo aponta então para a constituição de uma situação limite, definida em termos de alternativas dualistas, mutuamente exclusivas, que recebem avaliações opostas, de modo que o sentimento de crise pode ser espalhado, mas o diagnóstico e o prognóstico variam de acordo com quem usa o termo. Nessa operação, na qual o conceito é usado para definir alternativas históricas, ele se torna verdadeiramente um "conceito de combate", ou seja, a definição de crise vira uma arma no combate político e, pode-se acrescentar, torna-se a parte mais semiótica da luta política, sendo que os termos da definição comportam hierarquias de valor e oferecem justificações e um chamado para a ação.

Por aqui se vê um pouco do sentido do esforço de Koselleck para conceitualizar "crise". A sua hipótese básica é que o uso indiscriminado da palavra revela um mal-estar público, uma sensação de que "algo não vai bem", ainda que os termos que definem esse mal-estar não estejam bem estabelecidos (Koselleck, 2006). Para ele, a definição da crise é um terreno de disputa, uma controvérsia no plano da linguagem que é parte do combate político, em torno da qual cristalizam-se alternativas e se constitui uma demanda para a ação. É um conceito que cumpre uma função de diagnóstico e de avaliação, de modo que se relaciona diretamente com seu correlato, a crítica, que remete a uma percepção, uma perspectiva, um julgamento. 
Essa conexão fica ainda mais evidente quando pensamos que Crítica e crise se constitui não apenas como um estudo de história das ideias, mas explicitamente como um diagnóstico de época. A primeira frase do livro já aponta diretamente nesse sentido: "de um ponto de vista histórico, a atual crise mundial resulta da história europeia. A história europeia expandiuse em história mundial e cumpriu-se nela, ao fazer com que o mundo inteiro ingressasse em um estado de crise permanente" (Koselleck, 1999, p. 9). Mais adiante, ele afirma que "a crise política (...) e as respectivas filosofias da história (...) formam um único fenômeno cuja raiz deve ser procurada no século XVIII" (p. 9). Escrito em 1954, no contexto do debate alemão pós-Segunda Guerra, o livro avalia e explica os dilemas da "guerra fria" em conexão com a emergência da modernidade política europeia. A crise mundial, descrita como o estado de tensão permanente entre as duas potências vitoriosas, era o resultado de contradições intrínsecas à modernidade política, que não teria encontrado resposta adequada para a relação entre moralidade e política, de modo que as duas potências compreenderiam sua posição a partir de um conceito de superioridade moral e cultivariam a utopia de colonizar o espaço internacional à sua imagem e semelhança. A ideia de "patogênese" presente no subtítulo do livro sugere que a modernidade política burguesa nasceu com uma doença que levaria à crise, e que nela estão contidos elementos autodestrutivos: a contradição entre moralidade e política que não emerge ao plano da consciência, já que a sociedade civil burguesa se imagina apolítica e portadora de valores de superioridade moral. Essa inconsciência impediria a tomada racional de decisão política e a pacificação do conflito, o que se projeta em um espaço internacional povoado por dois "partidos" convictos de sua superioridade moral e que não aceitam outro resultado senão a supressão do adversário, razão pela qual o direito internacional sucumbiria a um estado de guerra civil. Sua imagem da crise da modernidade corrobora a proposição de uma crise permanente, que resulta de uma contradição imanente, que não se põe na esfera da relação capital-trabalho, como em Marx, mas na estrutura básica do arranjo político moderno. 
Koselleck (1999) monta seu problema em diálogo com a visão de Carl Schmitt sobre a guerra fria como uma "guerra civil mundial", $\mathbf{5}$ na qual as ideologias políticas proveem armas de combate decisivas para legitimar a ação política e militar. O fim da Segunda Guerra não seria assim o fim da crise, o presente é crise e a sociologia se torna ciência da crise, que possibilita investigar as causas e, em alguma medida, oferecer uma saída. As causas remetem às contradições imanentes da modernidade política. Já a terapia revela o teor normativo presente em sua reflexão e aqui ele não reproduz in toto a posição de Schmitt. Isso porque Koselleck (1999; 2006) não estaria a considerar a modernidade política em si mesma "ilegítima" ou inferior, nem compartilha a esperança de recuperar uma totalidade cosmológica perdida ou a política absolutista, que se torna alvo de sua crítica justamente pela incapacidade de incorporar politicamente a cidadania emergente. ${ }^{6}$ Sua agenda normativa estaria na busca de uma relação mais apropriada entre moral e política, na qual a participação política pudesse transformar os súditos em cidadãos com responsabilidade política. De acordo com Olsen (2014), ele teria uma admiração pela solução inglesa, como em Locke, que separava moral e política sem antagonizá-las, com um parlamento com representantes do rei e da sociedade, capaz de evitar a revolução, o que não ocorre na Europa continental, onde a polarização levaria à crise e cuja consciência de crise não se transformaria em decisão política "racional" e "responsável". Koselleck poderia assim combinar a ontologia schmittiana de uma sociedade essencialmente política e conflitiva com uma proposição normativa de que o conflito poderia ser contido pelo reconhecimento do pluralismo político, de modo que o antagonismo essencial da natureza humana poderia ser tratado com responsabilidade política e de modo menos assimétrico para não gerar exclusão e agressão.

A história dos conceitos de Koselleck revela-se, então, extremamente produtiva para pensar as ambiguidades do conceito de crise, bem como

${ }^{5}$ Sobre a recepção da tese de Schmitt da guerra fria como "guerra civil mundial" por Koselleck e a documentação da correspondência entre eles, ver Olsen (2014, p. 23 e ss.). ${ }^{6}$ Esta avaliação também está presente em Duarte (2012). 
para pensar a relação entre mudanças que ocorrem no âmbito da linguagem utilizada para pensar fenômenos e eventos, e mudanças na estruturação das relações políticas e sociais. Há, todavia, um viés um tanto construtivista em seu modo de conceber as crises, que tende a dissolver problemas mais objetivos nos modos de percepção e na linguagem. Desse modo, a dimensão da crítica é inflada como produtora de crises ${ }^{7}$ - isso para não falar no enviesamento de sua leitura histórica da crítica iluminista. Outra questão relevante é que seus diagnósticos de época e da modernidade política são bastante dependentes de uma ontologia de inspiração schmittiana, que essencializa a dimensão antagonista dos conflitos políticos na lógica amigoinimigo. Embora ele se aproxime de uma posição normativa mais aberta ao pluralismo e, ao longo do tempo, abandone o topos da "guerra civil mundial", ainda assim, a política se torna um espaço que é ao mesmo tempo essencial, pois decorrente de uma condição humana existencial, e pautado por uma racionalidade estratégica que calcula consequências a partir de critérios de responsabilidade e decide. Por isso, cabe perguntar se esta não é uma interpretação muito decisionista da reflexividade política, que secundariza demais possibilidades cognitivas e emancipatórias associadas a uma prática comunicativa mais aberta, inclusive aos impulsos morais presentes na crítica social, que são potencialmente causadores de crise ou responsivos a elas. Não seria então sua concepção de responsabilidade política muito afeita a um cálculo estratégico de consequências que assume feições, no limite, conservadoras? Nesse sentido, o debate com Habermas poderia ajudar a contrastar as concepções de crítica e de crise e oferecer um caminho mais atento às questões da "objetividade" da crise e do potencial da crítica.

\footnotetext{
${ }^{7} \mathrm{Na}$ recepção brasileira de Crítica e crise (Koselleck, 1999), destaca-se a resenha de Figueiredo (2000) que questiona o "dualismo" da crítica iluminista, cuja herança seria atual, entre a pura negatividade e o decisionismo estatal, que estaria a impedir a compreensão da política em sua dimensão própria e "imanente". Com isso, ele repõe a questão koselleckiana a respeito de uma crítica que, ao orientar-se por uma normatividade que transcende a normatividade própria da política, perderia a efetividade, e tornaria mais difícil a produção de consensos "mínimos efetivos". Essa posição, no entanto, como procuro argumentar, é pouco sensível às transformações dos quadros normativos oriundas da crítica social em contextos de crise.
} 


\section{Habermas, as tendências de crise e as possibilidades da crítica}

A formulação de Koselleck (1999; 2006) tem grande relevância para a história dos usos e do conceito de crise, e também para mostrar sua dependência em relação à noção de crítica e à perspectiva de quem usa o conceito. Crise pode ser, assim, um conceito de combate político em torno do qual se procura definir uma situação ou mesmo uma totalidade histórica mais ampla, podendo-se combinar no conceito uma tomada de consciência da historicidade de uma sociedade e a mobilização de vontades políticas. Entretanto, Koselleck (1999) possui uma visão muito negativa da modernidade política, ainda que distinta em grau e mesmo em conteúdo daquela esposada por seu grande interlocutor, Carl Schmitt, o que, no limite, pode conter um sentido politicamente conservador, pouco afeito a novas exigências oriundas da crítica social e mesmo da crítica democrática, que conferem um dinamismo político do qual sociedades modernas não podem, normativamente, abrir mão sem ferir expectativas emancipatórias presentes em movimentos sociais relevantes.

Creio ser possível mostrar como Habermas trabalhou com um conceito de crise mais amplo e aberto às dinâmicas da modernidade política, tanto no que diz respeito a aspectos sistêmicos e funcionais, quanto ao lugar da crítica, embora suas formulações também tenham dificuldades, em especial quando as conectamos com seus diagnósticos de época. Para isso, quero me ater ao debate que circunda seu Crise de legitimação no capitalismo tardio, publicado pela primeira vez em 1973. Mas, antes, é preciso observar que Habermas interpretou a emergência da modernidade política e de sua "esfera pública" em diálogo com Koselleck, mas de modo distinto. Conforme Cohen e Arato (1999 [1992], cap. 5), Habermas (2014a) vê mais heterogeneidade nas formas organizativas da esfera pública e nas variantes nacionais do Esclarecimento, de modo que a crítica de Koselleck à "hipocrisia" da crítica lhe parece unilateral. Enquanto Koselleck (1999) analisa especialmente as lojas maçônicas, com o compromisso de segredo 
entre seus membros, Habermas encontra a crítica ao Estado absolutista na formação de um "público" leitor de livros, revistas e jornais que se pauta por critérios de uma comunicação irrestrita e, aos poucos, assume funções políticas. Seu objetivo não é necessariamente a revolução, mas a sua própria institucionalização, com o estabelecimento de uma esfera protegida capaz de influenciar e controlar a autoridade estatal, isto é, alterar os princípios de organização do poder político de modo a restringir sua esfera de decisão, de acordo com uma linguagem de direitos fundamentais e por meio de procedimentos. Os casos inglês e alemão contrastam com o caso francês em que se baseou Koselleck - e, mesmo na França, o desenvolvimento da esfera pública percorre outros caminhos, mais expostos ao liberalismo, para além do período revolucionário. A institucionalização da esfera pública no parlamento completa o argumento histórico, mostrando inclusive que as demandas de liberdade de expressão e organização política, bem como o direito ao voto, inicialmente atreladas aos proprietários burgueses, não se restringem a eles, mas abarcam os estratos não incluídos formalmente nas instituições, apontando um processo de democratização, no qual o público permanece desenvolvendo suas capacidades críticas (Cohen; Arato, 1999 [1992]; Habermas, 2014a).

Para Habermas (2014a), esse processo não é isento de contradições estas apontam, contudo, para as fronteiras entre Estado e sociedade civil, entre a emergente economia burguesa de indivíduos privados orientados para um mercado livre do paternalismo e das intervenções estatais e as funções estatais necessárias para protegê-la - o paradoxo de um Estado que intervém para liberar a sociedade civil de antigas formas de intervenção, de um poder que precisa agir para criar a sensação de que não age. Ou, ao menos, não arbitrariamente. A ideia de uma esfera pública racional, capaz de orientar racionalmente o governo e a produção das leis, oferece um modelo para a relação entre sociedade e Estado que não se restringe ao campo econômico, mas estabelece um conjunto de direitos constitucionais mais amplos que, idealmente, favorece a participação política e garante centralidade a essa mesma esfera pública no processo político. Ainda 
que essa última não se generalize de imediato, as normas de publicidade dificultam a manutenção dos mecanismos de exclusão de classes e estratos sociais específicos, de modo que o caráter "utópico" da esfera pública burguesa se torna a base para uma crítica imanente e sua normatividade não se configuraria mera ideologia, mas um suporte para a transformação das instituições políticas. Cohen e Arato (1999 [1992]) expõem as dificuldades da tentativa de Habermas de combinar as posições normativas do marxismo e do liberalismo na mesma forma de crítica, que acaba por não levar em conta que a crítica marxista não é puramente imanente, já que rejeita o processo de diferenciação entre público e privado no qual está assentada a emergência da esfera pública burguesa.

O argumento de Habermas (2014a) completa-se com a tese do declínio da esfera pública, a partir das novas funções estatais que "politizam" a economia e da transformação no conceito de opinião pública que, por sua vez, "despolitiza" a participação da cidadania. Perde-se o nexo entre os processos comunicativos de formação da opinião aos quais as instituições estariam normativamente atreladas, com isso a opinião pública se decompõe, por um lado, em redes informais e, por outro, em objeto da administração pública e das técnicas de publicidade que procuram medir comportamentos e agir sobre eles. Sua conclusão revela uma avaliação que seria formulada e reformulada, com diferentes matizes, ao longo de sua trajetória e que remete às ameaças que a "tecnocracia" representa ao ideário normativo da modernidade política, aos dilemas decorrentes do desenvolvimento de tecnologias administrativas, que fazem parte do processo de modernização e podem subtrair dos cidadãos a capacidade de crítica e deliberação. Em Teoria e práxis (Habermas, 2013) esta preocupação está no cerne de sua crítica da filosofia política, que se desenvolve ao longo dos pressupostos de uma racionalidade técnica voltada para a administração da ordem. Com isso, a política se configuraria como objeto de um pensamento científico, tal como no modelo hobbesiano, que procura combinar "leis da natureza" e "leis da razão". Mas, ao refletir sobre suas consequências apenas do ponto 
de vista organizativo e tecnológico, a política perde de vista o horizonte dos cidadãos, de suas perspectivas e formas de conhecimento (Habermas, 2013).

Nesse contexto, a reflexão mais sistemática sobre a crise se dá em Crise de legitimação no capitalismo tardio (Habermas, 1988). Nesse livro, a recensão inicial do conceito aponta para as limitações de perspectivas unilaterais, e defende que a teoria precisa captar a conexão entre problemas de integração social e de integração sistêmica. As crises têm uma existência objetiva quando se referem a "problemas de controle". Na teoria dos sistemas, a crise se relaciona à escassez de recursos para a solução de problemas capaz de assegurar a continuidade das operações. Todavia, haveria aí uma falta de teorização sobre as causas da escassez, já que elas costumam estar relacionadas a contradições internas que afetam estruturas essenciais, cuja alteração levaria a mudanças na identidade dos sistemas. Quando comparada com a biologia, cujos sistemas são organismos materialmente bem definidos no tempo e no espaço, essa conceitualização tem problemas, pois os sistemas sociais se constituem em ambientes hipercomplexos e podem assegurar sua continuidade por meio de processos que alteram em profundidade seus elementos, objetivos e formas de controle, sendo que isso pode ser feito tanto por formas de desintegração e colapso quanto por meio de processos de aprendizagem e mudança - nem toda mudança em sistemas sociais pode ser considerada "crise". O ponto de vista "objetivista" não conseguiria captar os graus de tolerância quanto à transformação de valores centrais, que podem variar imensamente afetando ou não a identidade dos sistemas sociais (Habermas, 1988).

De uma outra perspectiva, poderíamos falar de crises "apenas quando membros de uma sociedade experimentam alterações estruturais como críticas para a existência continuada e sentem sua identidade social ameaçada" (Habermas, 1988, p. 3). Isso ocorre quando distúrbios sistêmicos colocam em questão a integração social, afetando estruturas normativas consensualizadas e produzindo estados de anomia, nos quais a crise assume a forma de desintegração das instituições. Todavia, essa perspectiva acaba se revelando "idealista" e tem suas dificuldades, seja porque a 
ruptura em tradições culturais ou estruturas normativas consensualizadas é um critério problemático, já que tradições culturais estão sempre em movimento, ou porque uma sociedade não entra em crise apenas quando seus membros identificam conscientemente a situação como tal. Crises têm sua objetividade, como problemas de controle que, mesmo quando não são inteiramente conscientes, afetam a consciência social de modo específico, criando problemas de integração social. Assim, a crítica de duas perspectivas unilaterais, a de teorias dos sistemas ou de teorias compreensivas e da ação, leva Habermas (1988) ao problema da conexão entre problemas materiais de controle e estruturas normativas. Ele propõe então uma análise histórica do desenvolvimento dos sistemas sociais em que processos de desenvolvimento e racionalização das forças produtivas e dos mecanismos de socialização se conectariam por meio de processos evolutivos de aprendizagem centrados em reivindicações discursivas de validade, que permitem ampliar o controle sobre a natureza externa e sobre a integração social, ou seja, a história do desenvolvimento científico-tecnológico e do desenvolvimento cultural, por meio dos quais a humanidade aprende a lidar com problemas. Assim, ele oferece uma teoria evolutiva dos sistemas sociais, formulada em termos de uma lógica de diferenciação social que permite a separação dos mecanismos de integração social e sistêmico, com suas lógicas próprias, e do desenvolvimento dos sistemas de legitimação da autoridade e da ordem - o que constitui um modelo bastante abstrato de mudança social, cujas possibilidades de generalização são duvidosas.

Mas o modelo serve para situar sua compreensão de como o "capitalismo tardio" aprendeu a lidar com os problemas de controle econômico do capitalismo liberal, descritos por Marx, que ameaçavam a continuidade não apenas das operações sistêmicas, mas da integração social. Para tanto, Habermas (1988) recorre a uma teoria do capitalismo organizado ou regulado pelo Estado, que apresenta modificações substanciais em relação à modelagem liberal, devido à concentração econômica em grandes corporações e à regulação estatal, que enfraquecem os mecanismos competitivos, embora não os mecanismos de mercado como condutores 
do investimento empresarial. Nessa formação, o sistema administrativo ganha nova relevância ao lidar com os imperativos do sistema econômico via regulação e planejamento, substituindo alguns dos mecanismos do mercado competitivo. Com isso, o sistema econômico volta a estar ligado ao político: a ideologia da troca livre colapsa e o engajamento do Estado na economia exige novas formas de legitimação da autoridade política, que serão buscadas na institucionalização de uma democracia de baixa intensidade participativa e num regime de compensações econômicas que arrefecem o conflito de classes, mas não eliminam o potencial de crises.

No capitalismo avançado, a crise potencial decorre tanto de problemas internos à operação dos sistemas, quanto de efeitos do sistema sobre outras esferas - sobre os quais, entretanto, Habermas (1988) tem pouco a dizer -, nomeadamente a crise ecológica, o "equilíbrio antropológico" e o balanço de poder internacional. Seu interesse está nas crises sistêmicas e na lógica de seu encadeamento. Nesse regime, a mediação estatal é o fator decisivo para planejar e prevenir crises econômicas, mas há limites para sua ação frente aos mecanismos sistêmicos, e nem sempre é possível compensar as tendências de queda da taxa de lucro do investimento privado, o que leva a desequilíbrios no circuito de valorização, com consequências sociais.

Os agentes econômicos tendem a transferir problemas sistêmicos para a administração, que, assim, opera com imperativos de controle contraditórios, os quais só podem ser compensados se houver um encontro entre as racionalidades de agentes que negociam estrategicamente a fim de evitar crises. A administração precisa conseguir motivar os agentes a cooperar, o que não é simples, pois há comportamentos que regularmente ameaçam a racionalidade administrativa. A existência de um espaço para a regulação faz com que a crise administrativa não seja, a priori, inevitável. Crises sistêmicas seriam possivelmente contornáveis, passíveis de previsão e controle administrativo, antes ou depois de sua emergência, ainda que não se possa excluir a possibilidade de falha administrativa. Os limites à regulação não são intrínsecos à racionalidade administrativa, mas são de ordem política. As crises econômicas são transferidas para o sistema 
político, que procura usar recursos de poder legítimo para compensar os déficits de racionalidade administrativa ou, ao contrário, utiliza programas administrativos para produzir legitimação, quando essa é escassa. Os limites da administração vêm da capacidade fiscal do Estado, ou da motivação dos cidadãos, mas não necessariamente levam à crise.

O sistema cultural contribuiria para a estabilização do capitalismo organizado por meio da orientação dos cidadãos e das famílias para o consumo, para as carreiras profissionais em que reproduzem a competição por status e as lógicas de desempenho individual. O Estado tenta planejar ideologicamente a vida cultural por meio de técnicas publicitárias, mas há resistências; temas que não estavam na agenda pública entram em pauta e o planejamento administrativo não é suficiente para organizá-los. Crises de legitimação emergem, então, quando a administração não consegue suprir demandas programáticas da população, a qual a penaliza com a retirada da legitimação, o que, por sua vez, reduz ainda mais a margem de ação sistêmica.

No contexto europeu pós maio de 68, Habermas (1988) observa mudanças sociais que estariam a afetar componentes significativos da ideologia no que diz respeito ao desempenho escolar e profissional, aos padrões de justiça e de avaliação, às lógicas do consumo e da socialização. São tradições culturais que se movem e apontam para divergências entre os valores oferecidos pelos sistemas político e econômico e pelo sistema sociocultural. O avanço do espírito científico e de padrões morais mais universalizantes levariam as estruturas normativas a se mostrarem mais dependentes de necessidades de justificação. Assim, elas passariam a conformar padrões de socialização menos tradicionais e mais reflexivos, que estariam na raiz do potencial de protesto dos jovens, e apontariam para crises de "motivação", nas quais os resultados alcançados no nível sociocultural são "desfuncionais" para a continuidade das operações sistêmicas.

O sistema político no capitalismo organizado só conseguiria estabilização se pudesse produzir sua própria legitimação, a partir de sua performance, sem a necessidade de recurso a justificações normativas, às quais estão atados 
os estados constitucionais e que fundamentam a adesão dos indivíduos às normas. Teorias elitistas da democracia, centradas no pluralismo de elites e na competição, procuram elidir a necessidade de justificação, retendo-se apenas no aspecto da competição eleitoral. Teorias dos sistemas também escapam às necessidades de conexão entre a produção de decisões políticas e a justificação racional de seu conteúdo na esfera pública. Ambas evitam fundamentar comunicativamente a legitimidade das normas e decisões e tendem a reduzir a participação do público, assentando a legitimação apenas na legalidade formal. Se isso se estabelece, os requisitos sistêmicos poderiam prover por si mesmos as motivações para a tomada de decisões e para a ação, independentemente de estruturas normativas apoiadas em interesses generalizáveis reconhecidos pelos participantes de um processo comunicativo. A racionalização da administração poderia se dar de modo independente da política, da formação coletiva da vontade. Entretanto, os custos de uma tal evolução social, assentada apenas na integração sistêmica, seriam muito elevados para a reflexividade e, no limite, para a dignidade humana. Contra essas concepções, Habermas (1988) busca recuperar um lugar para a formação da vontade política atrelada à participação dos cidadãos e à possibilidade de acessar, pela comunicação racional pública, a veracidade das reivindicações de validade em questões práticas.

A análise dos potenciais de crise do capitalismo tardio fornece os elementos do diagnóstico de época, formulado na sequência dos protestos estudantis de 1968. Em síntese, a dinâmica econômica já não conduz, por si, à crise, que não se explica pelas contradições intrínsecas ao processo de acumulação, já que a racionalização da economia, através do planejamento administrativo, antecipa os efeitos da crise e age sobre eles. A crise se desloca para o sistema político, que precisa lidar com imperativos contraditórios e vê sua margem de manobra reduzida, o que leva a falhas ou a problemas de legitimidade. Esses se tornam mais graves quando analisados sob a ótica das transformações no sistema sociocultural, com as tradições sendo postas em movimento, num processo reflexivo que evita o conformismo político e que amplia a pressão sobre modos de socialização conformes ao planejamento 
estatal. Ainda que formulado na linguagem "social-científica", o diagnóstico de Habermas não trai a identificação de um potencial crítico nos modos de vida que tenderiam a pressionar os sistemas em direção à ampliação das formas de participação política e à liberação das formas de socialização de padrões tradicionais. A ideia de um aprendizado social no modo de lidar com problemas de integração forneceria uma saída progressiva para a dinâmica das crises e da mudança social, na qual a economia capitalista não é posta diretamente em xeque, mas as tendências críticas e reflexivas apontariam possibilidades de democratização. Elas encontram resistência nas tendências tecnocráticas que compreendem as crises apenas como problemas de controle e não consideram possível um debate racional de objetivos e questões práticas, são refratárias à ampliação da participação, que significaria apenas maior complexidade e dificuldade de decisão.

Mas, o diagnóstico de época, em seu sentido mais estrito, falhou. A expectativa de que uma socialização mais reflexiva apresentasse desafios políticos de monta ao capitalismo tecnocrático não se afirmou. O próprio ambiente político da Alemanha no final dos anos de 1970 seria bastante distinto, marcado pela revitalização do "neoconservadorismo", o que motivaria um vasto esforço de compreensão e debate público por parte de Habermas (Müller-Doohm, 2016, cap. 6). Com o tempo perceberíamos que o sistema se revelou capaz de produzir compensações ao nível do consumo e de revitalizar elementos ideológicos atrelados ao mérito e ao desempenho que, mesmo em um ambiente mais reflexivo em relação aos elementos tradicionais nos modos de vida, forneceram justificações e renovaram as possibilidades de acumulação. Nos termos de Boltanski e Chiapello (2009), o capitalismo absorveu a "crítica artística" em suas metamorfoses e neutralizou a "crítica social" centrada nos problemas distributivos. A combinação capitalismo e democracia no mundo euro-americano se fortaleceria, ainda que a estrutura do capitalismo passasse por transformações que, com o tempo, se revelariam tendentes ao crescimento da desigualdade, e que a democracia enfrentasse a malaise da baixa participação. As ondas sucessivas de "democratização" na Iberoamérica, no Leste europeu e mesmo na Ásia e 
na África, estiveram na base das esperanças democratizantes de Habermas - e de muitos outros - nos anos de 1990, enquanto a globalização dos mercados projetava os desequilíbrios econômicos para bem além dos estados nacionais e de sua capacidade reguladora.

Mais recentemente, após o crash financeiro de 2007-2008, o problema das crises de legitimação retornaria à pauta. Revelou-se, aí, outra limitação do diagnóstico habermasiano de 1973, a incapacidade da racionalidade administrativa estatal de antecipar ou lidar com os distúrbios sistêmicos (Streeck, 2014). As transformações estruturais provocadas pela expansão da economia capitalista no globo minaram as condições de possibilidade da ação estatal, o espaço econômico nacional evanesce, reduzindo capacidades efetivas de controle do Estado nacional. Novos problemas de controle se apresentam com as perturbações na dinâmica dos sistemas, afetando mecanismos de integração social e modos de vida. Em seu debate com Streeck, Habermas (2014b, cap. 9) reconheceu a confiança excessiva nas possibilidades do planejamento, mas já não considera possível a retomada da condição anterior, procurando uma saída superadora da crise do capitalismo global no aprofundamento da democracia no plano transnacional.

Também Nancy Fraser $(2015 ;$; 2017) retoma recentemente elementos da formulação habermasiana a respeito da crise. Sua abordagem mantém uma concepção de crise atrelada às formas de estruturação da "ordem capitalista", vista também como uma formação social. Ela traz algumas contribuições novas à caracterização do problema, ao enfrentar as "condições de possibilidade" da acumulação capitalista que remetem a esferas sociais não inteiramente mercantilizáveis e subsumidas à lógica do capital, quais sejam, a família como fonte de trabalho social não assalariado, os poderes públicos atrelados a exigências de cidadania e de proteção/integração social e o ambiente ecológico. Seu trabalho subverte a separação inicialmente proposta por Habermas entre problemas sistêmicos e seus efeitos, mostrando como aquilo que é aparentemente externo à dinâmica de acumulação, constitui condições sem as quais a dinâmica sistêmica não seria possível. Fraser pode, assim, retomar proposições de crise imanente, mas formulá-las 
com referência não apenas à performance do sistema e suas irracionalidades, mas em conjunção com a estruturação da ordem social assentada nessas separações. E, como essas esferas não seriam simplesmente funcionais à acumulação, mas possuem sua legalidade própria, elas se constituem em referência normativa para a crítica. Essa forma de abordagem também aponta, como em Jaeggi (2017), as dificuldades para uma teoria crítica de se conceber a economia como uma esfera normativamente neutra, o que tende a neutralizar a possibilidade da crítica.

\section{Notas finais}

Essas são algumas direções que o debate contemporâneo sobre crise e crítica poderia tomar, reformulando os diagnósticos de época e procurando avançar em direção a uma boa teoria das crises no capitalismo e na modernidade política - uma que fosse sensível ao problema da crítica e capaz de participar de uma reflexividade social mais ampla. Habermas e Koselleck oferecem um bom ponto de partida para a compreensão do conceito de crise, que é parte de seus esforços de produção de diagnósticos de época e de compreensão de tendências de mudança social. Até aqui, procuramos mostrar que Koselleck (1999; 2006) esclarece a história semântica do conceito de crise e a diversidade de seus usos em contextos distintos, como arma de combate político, bem como na compreensão e avaliação do tempo histórico. Há, contudo, certa conflação entre crítica e crise, que tenderia a uma hiperinflação da capacidade da crítica na produção de crises. Sua concepção do "político" com exigências fortes de separação entre política e moralidade seria também pouco sensível à força normativa e politicamente transformadora da crítica social, elemento decisivo da dinâmica moderna, com o risco de aproximá-lo excessivamente de teorias conservadoras da crise, que a concebem como um problema de governabilidade. Habermas (1988) oferece uma alternativa aos dois pontos, concebendo a crise como uma conjunção de problemas de controle e normativos, que poderia servir melhor de modelo para lidar com problemas funcionais e com a diversidade 
de interpretações e experiências de crise. A relação entre crítica e política é mais bem concebida tendo lugar em um modelo de esfera pública com funções políticas e mais aberto às reivindicações transformativas da crítica social. A partir dos dois autores, é possível propor que:

1) "crise" é um conceito que se tornou parte do vocabulário dos "diagnósticos de época" da modernidade e que deve ser compreendido no escopo de teorias dos processos e das mudanças sociais; assim, é um conceito que aponta para características estruturais e para tendências de desenvolvimento das sociedades modernas, que se desdobram no tempo e afetam de modo mais amplo instituições e relações sociais. Em sentido mais restrito, crises se relacionam com problemas de controle que envolvem recursos escassos e afetam rotinas e operações sistêmicas. No entanto, crises dizem respeito a experiências subjetivas formuladas linguisticamente, que compõem um quadro cultural e normativo e que envolvem avaliações, interpretações, tentativas de definição ou de redefinição de uma situação ou de um conjunto de relações. Nesse sentido, crise é um conceito que circula entre a linguagem sociológica e as linguagens dos atores e das instituições. Como mostra a história do conceito em Koselleck (1999; 2006), ele não se estabiliza, e a luta pela definição de crise é parte da própria crise e dos conflitos políticos. Esta instabilidade pode motivar um criticismo anticrise que vê no conceito de crise um artifício narrativo para permitir a própria elaboração da história em sua concepção moderna, isto é, para dar significado histórico a eventos. Crise seria um termo que estabelece observações de segunda ordem, que permitem distinguir e localizar contradições e paradoxos, elaborados em termos de falhas éticas ou sistêmicas e estabelecer o terreno da crítica (Roitman, 2016). Narrativas de crise importam e Koselleck (2006) é convincente ao mostrar que há certa estrutura comum a elas. Todavia, crises têm sua materialidade e conexões com formas de estruturação do ordenamento social que devem ser levadas em conta em si mesmas.

2) A tentativa de pensar crises como parte de uma teoria dos processos e da mudança social está, de certo modo, relacionada à ideia de que há 
períodos de "não crise". Se esse contraste pretende ter alguma densidade, seria preciso evitar a compreensão de que períodos de "não crise" significam estabilidade ou harmonia, ou, pior ainda, "normalidade". Ao contrário, as grandes teorias de crise, de Marx a Habermas e Koselleck, apontam justamente para esse sentido de instabilidade latente na produção e reprodução da ordem social, para contradições e conflitos, quebras de rotina e mudança, que não se limitam aos períodos de crise. Rodrigo Cordero (2014) expõe com clareza que as teorias de crise nesses autores são argumentos em favor de uma compreensão da fragilidade da ordem social e não produtoras de um contraste estático entre estabilidade e instabilidade. Dessa forma, a relação entre períodos de crise e de não crise deveria ser vista de modo mais contínuo que descontínuo (Dobry, 2014). Crises dependeriam de certa conjunção de problemas estruturais e de controle, que se expressam nas operações sistêmicas e institucionais, e da experiência subjetiva crítica, que descreve o mundo social, produz sentido para as experiências vividas e expressa avaliações e diagnósticos de problemas e alternativas. Em períodos de crise há menor objetivação das relações sociais, maior contingência e incerteza - razão pela qual Dobry (2014) prefere o termo "conjunturas fluidas", bastante apropriado para crises políticas. Essa incerteza, na perspectiva dos atores, significa que conhecimentos antes tidos como garantidos não o são mais, o que motiva buscas de reestabilização de sentido, que nem sempre se concretizam. Em períodos de crise, estruturas opacas tornam-se mais visíveis para os atores - o que as torna, conforme Bhaskar (apud Jessop, 2016, p. 93), um laboratório metodologicamente tão interessante para as ciências sociais investigarem a dialética entre semiótica e materialidade, entre agência e estrutura, entre dominação e emancipação. Crises são, assim, momentos de "desobjetivação", momentos "tranformativos" - e os grandes movimentos sociais respondem a crises ou produzem crises (Benhabib, 2019).

3) Crises envolvem sempre uma avaliação crítica, mas há múltiplas formas de reflexividade envolvidas em situações ou períodos de crise que, sem pretensão exaustiva, poderíamos mapear: a) crises podem ser 
concebidas, da perspectiva de atores estratégicos, como oportunidade para a ação estratégica em torno do controle de recursos e de poder - situação cujo modelo é a guerra, como bem percebeu Koselleck (2006); b) ainda da perspectiva da ação estratégica, crises podem ser o resultado (consciente ou inconsciente) da mobilização de atores que competem por recursos e alteram rotinas e lógicas estabelecidas em "setores", esferas ou instituições da vida social, como percebido por Dobry (2014); c) crises podem desencadear comunicações voltadas para o aprendizado e a solução de problemas sistêmicos; d) crises podem desencadear processos comunicativos mais amplos, que despertam a consciência pública sobre problemas, como, por exemplo, nas formulações do pragmatismo de Dewey (1993) ou na modelagem de esfera pública de Habermas (2011; 2014a); e e) crises podem ser o resultado da reflexividade de indivíduos ou grupos sociais sobre situações ou padrões de relação entendidos como "desrespeito", seja por conta de transformações institucionais que afetam padrões normativos, como mostrou Thompson (1998) em sua discussão sobre a economia moral, seja por transformações nas expectativas e padrões culturais e normativos, tal como proposto por Habermas (1988) e Honneth (2009). Nem todas essas possibilidades de reflexividade são o que se poderia chamar de "crítica", conceito que parece restrito às duas últimas, mas todas elas envolvem alguma relação entre problemas de controle e experiências subjetivas.

4) A relação entre crise e crítica deve ser formulada sem que uma esteja subsumida à outra, de modo a evitar uma conflação conceitual na qual a crise não é senão o resultado de um discurso crítico. A ênfase de Koselleck (1999) no papel da crítica pode levar a essa interpretação que, no entanto, não está explicitada teoricamente. É controverso também o quanto essa seria uma boa descrição do argumento de Luhmann (1984), pois, embora sejam conhecidas suas posições críticas a respeito de autodescrições "negativas" da sociedade, ele não seria insensível a problemas sistêmicos decorrentes da ausência de reflexividade, a reprodução irrefletida que tende a reduzir a contingência, sufocar a produção semântica e eliminar referências ao futuro ou ao "ambiente externo" (as expectativas dos observadores), produzindo 
homogeneização e redução do potencial de diferenciação social (Cordero; Mascareño; Chernilo, 2017). O que tanto Luhmann (1984) quanto Koselleck (1999) parecem deplorar - e não só eles - é um descolamento da crítica de um terreno imanente, a cisão entre o "horizonte de expectativas" e o "campo de experiências" ou a "oscilação" e "desvio para o futuro", que caracterizariam um pensamento utópico. Esta concepção de utopia não faz jus, todavia, à concepção de crítica em Habermas (2012) e na tradição da teoria crítica, que lida com uma dialética imanência-transcendência que busca evitar os riscos de uma imaginação puramente utópica, sem, contudo, abrir mão das energias transformadoras que as utopias, a crítica social ou as reivindicações de justiça podem carregar. Nessa linha, as comunicações normativas tornam-se decisivas para a energização do mundo social e podem desencadear modos de reflexividade que ofereçam possibilidades de uma autoprodução social mais consciente.

Esta formulação não é isenta de ambiguidades. Por um lado, há todo um conjunto de questões que dizem respeito à relação entre a reflexividade dos intelectuais e os sentimentos e os quadros normativos e morais comuns - as múltiplas hermenêuticas entre a agência crítica dos intelectuais e a dos movimentos sociais ou mesmo dos indivíduos, que têm estimulado uma produtiva sociologia da crítica (Boltanski, 2011). Por outro, um ponto de vista crítico e uma teoria da crise devem lidar necessariamente com as questões da política e do poder. Seja porque as operações sistêmicas não são neutras em relação ao poder e à dominação, seja porque a política, ou "o político", constituiu-se historicamente como uma forma secularizada das sociedades de produzir um saber e de agir sobre si mesmas. A questão torna-se ainda mais dramática quando se percebe que as crises contemporâneas podem ser descritas não só em termos de crise da economia capitalista, mas também dos estados nacionais, que concentraram historicamente as "capacidades" de ação consciente das sociedades sobre si mesmas na escala nacional. O quadro teórico de referência de Koselleck (1999; 2006), com sua ontologia bastante schmittiana, tende a deflacionar as possibilidades da crítica em um processo comunicativo mais amplo, estreitando as possibilidades de 
compreensão da política. Com Habermas $(1988 ;$ 2011; 2012) e contra Koselleck (1999), seria possível conceber a ação política como uma agência crítica cujo sentido não se esgota na "negatividade" dos processos de dominação, mas se estende para possibilidades comunicativas e participativas mais amplas de sentido emancipatório. A democracia ultrapassa a fronteira do pluralismo e da competição para ser concebida como uma forma de conexão do poder político com exigências de justificação, legitimação e participação ampliadas, que apontam, no limite, para a democracia como uma forma de vida. Nesse sentido, "o político" não desaparece nas sociedades complexas, como forma de identidade e imaginação das sociedades em relação a si mesmas. No entanto, seu lugar se altera, com a força normativa de Constituições democráticas, com a incorporação de uma reflexividade social para além do Estado, mas que mantém vínculos participativos com as instituições. Sua única base transcendente seria o "uso público da razão" que permite conectar problemas públicos com o fluxo comunicativo que vem "de baixo" e impulsiona transformações (Habermas, 2011).

Emparedadas entre o autoritarismo e a tecnocracia, que conformam, ambos, o pano de fundo de tendências atuais de desdemocratização, as reivindicações normativas da teoria crítica em torno da democracia participativa atravessam momento particularmente difícil, embora as conquistas democráticas obtidas no plano da cultura política e da socialização não possam ser tão facilmente apagadas. Mesmo em seu campo político originário, que é o da esquerda e dos movimentos sociais, cresce o desafio posto por concepções schmittianas de crise, que reivindicam um "momento populista", apelam para formas de ação dramáticas e flertam com concepções de representação política carismáticas e totalizantes que parecem, por vezes, um espelho invertido de seus adversários. Quando transposta para o plano da ação, entretanto, a discussão sobre o conceito de crise não pode senão ajudar a esclarecer as posições, seus limites ou o preço das escolhas, na esperança de que a continuidade da controvérsia ajude a encontrar melhores caminhos. Crises, assim como os totens, são boas para pensar! 
Felipe Maia é Doutor em Sociologia pelo IESP-UERJ e Professor do Departamento de Ciências Sociais da Universidade Federal de Juiz de Fora.

\fmaia@yahoo.com

\section{Referências}

1. BENHABIB, Seyla. Abaixo do asfalto está a praia: reflexões sobre o legado da Escola de Frankfurt. Cadernos do Ateliê, v. 1, p. 1-21, 2019.

2. BOLTANSKI, Luc. On critique: a sociology of emancipation. Cambridge: Polity, 2011.

3. BOLTANSKI, Luc; CHIAPELLO, Éve. O novo espírito do capitalismo. São Paulo: Martins Fontes, 2009.

4. COHEN, Jean L.; ARATO, Andrew. Civil society and political theory. Cambridge: The MIT Press, 1999.

5. CORDERO, Rodrigo. Crisis and critique: on the fragile foundations of social life. Londres: Routledge, 2014.

6. CORDERO, Rodrigo. Crisis and critique in Jürgen Habermas's social theory. European Journal of Social Theory, v. 17, n. 4, p. 497-515, 2014.

7. CORDERO, Rodrigo; MASCAREÑO, Aldo; CHERNILO, Daniel. On the reflexivity of crises: lessons from critical theory and systems theory. European Journal of Social Theory, v. 20, n. 4, p. 511-530, 2017.

8. DEWEY, John. The political writings. Indianapolis: Hackett Pub. Co, 1993.

9. DOBRY, Michel. Sociologia das crises políticas. São Paulo: Ed. UNESP, 2014.

10. DUARTE, João de A. e D. Tempo e crise na teoria da modernidade de Reinhart Koselleck. História da Historiografia: International Journal of Theory and History of Historiography, n. 8, p. 70-90, 2012.

11. FIGUEIREDO, Vinicius de. O dualismo da crítica. Revista de Sociologia Política, n. 15, p. 125-30, 2000.

12. FRASER, Nancy. Behind Marx's hidden abode: for an expanded conception of capitalism. In: DEUTSCHER, Penelope.; LAFONT, Cristina (orgs.). Critical theory in critical times: transforming the global political and economic order. New directions in critical theory. Nova York: Columbia University Press, 2017. p. 141-159.

13. FRASER, Nancy. Legitimation crisis? On the political contradictions of financialized capitalism. Critical Historical Studies, v. 2, n. 2, p. 157-189, 2015.

14. HABERMAS, Jürgen. Introduction. In: HABERMAS, Jürgen. Observations on 'the spiritual situation of the age'. Cambridge: MIT Press, 1987. p. 1-29.

15. HABERMAS, Jürgen. Legitimation crisis. Cambridge: Polity Press, 1988. 
16. HABERMAS, Jürgen. "The political": the rational meaning of a questionable inheritance of political theology. In: MENDIETA, Eduardo; ANTWERPEN, Jonathan van. (orgs.). The power of religion in the public sphere. Nova York: Columbia University Press, 2011. p. 15-33.

17. HABERMAS, Jürgen. Teoria do agir comunicativo. São Paulo: Martins Fontes, 2012.

18. HABERMAS, Jürgen. Teoria e práxis. São Paulo: Editora Unesp, 2013.

19. HABERMAS, Jürgen. Mudança estrutural da esfera pública. São Paulo: Editora Unesp, 2014a.

20. HABERMAS, Jürgen. Na esteira da tecnocracia. São Paulo: Ed. UNESP, 2014 b.

21. HABERMAS, Jürgen, A sociologia na República de Weimar. In: Textos e Contextos. São Paulo: Ed. UNESP, 2015. p. 275-305.

22. HAMMERSHOJ, Lars G. Diagnosis of the times vs description of society. Current Sociology, v. 63, n. 2, p. 140-54, 2015.

23. HONNETH, Axel. Luta por reconhecimento: a gramática moral dos conflitos sociais. 2. ed. São Paulo: Editora 34, 2009.

24. JAEGGI, Rahel. A wide concept of economy: economy as a social practice and the critique of capitalism. In: DEUTSCHER, Penelope; LAFONT, Cristina (orgs.). Critical theory in critical times: transforming the global political and economic order. New directions in critical theory. Nova York: Columbia University Press, 2017. p. 160-179.

25. JESSOP, Bob. The symptomatology of crisis: some critical realist reflections. In: NASS, Petter; PRICE, Leigh (orgs.). Crisis system: a critical realist and environmental critique of economics and the economy. Ontological explorations. Londres: Routledge, Taylor \& Francis Group, 2016. p. 89-108.

26. KOSELLECK, Reinhart. Crítica e crise: uma contribuição à patogênese do mundo burguês. Rio de Janeiro: UERJ; Contraponto, 1999.

27. KOSELLECK, Reinhart. Crisis. Journal of the History of Ideas, v. 67, n. 2, p. 357-400, 2006.

28. LICHTBLAU, Klaus. Soziologie und Zeitdiagnose. In: LICHTBLAU, Klaus. Zwischen Klassik und Moderne. Wiesbaden: Springer, 2017. p. 57-79.

29. LUHMANN, Niklas. The self-description of society: crisis fashion and sociological theory. Comparative Sociology, v. 25, n. 1, p. 59-72, 1984.

30. MANNHEIM, Karl. Diagnosis of our time. Nova York: Routledge, 2010.

31. MÜLLER-DOOHM, Stefan. Habermas: a biography. Cambridge; Malden: Polity, 2016.

32. OLSEN, Niklas. History in the plural: an introduction to the work of Reinhart Koselleck. Nova York: Berghahn, 2014. 
33. ROITMAN, Janet. The stakes of crisis. In: KJAER, Poul F.; OLSEN, Niklas (eds.). Critical theories of crisis in Europe: from Weimar to the Euro. Reinventing critical theory. Londres: Rowman \& Littlefield International, 2016. p. 17-34.

34. RUNCIMAN, David. What time frame makes sense for thinking about crises? In: KJAER, Poul F.; OLSEN, Niklas (eds.). Critical theories of crisis in Europe: from Weimar to the Euro. Reinventing critical theory. Londres: Rowman \& Littlefield International, 2016. p. 3-16.

35. STREECK, Wolfgang. Buying time: the delayed crisis of democratic capitalism. Nova York: Verso, 2014.

36. THOMPSON, Edward P. A economia moral da multidão inglesa no sec. XVIII. In: THOMPSON, Edward P. Costumes em comum. São Paulo: Companhia das Letras, 1998. p. 150-202.

37. WAGNER, Peter. Modernity: understanding the present. Cambridge; Malden: Polity, 2012.

38. WALBY, Sylvia. Crisis. Cambridge; Malden: Polity Press, 2015.

39. WALLERSTEIN, Immanuel M. Does capitalism have a future? Oxford; Nova York: Oxford University Press, 2013. 